\title{
Functional Development of Fat Absorption in Term and Preterm Neonates Strongly Correlates with Ability to Absorb Long-Chain Fatty Acids from Intestinal Lumen
}

\author{
EDMOND H.H.M. RINGS, DEANNE M. MINICH, ROEL J. VONK, FRANS STELLAARD, \\ WILLEM P.F. FETTER, AND HENKJAN J. VERKADE
}

Division of Neonatology, Department of Pediatrics, Isala Hospitals, Sophia Hospital Zwolle, 8000 GK Zwolle, The Netherlands [E.H.H.M.R., W.P.F.F.]; and Department of Pediatrics, Academic Hospital Groningen, 9700 RB Groningen, The Netherlands [E.H.H.M.R., D.M.M., R.J.V., F.S., H.J.V.]

\begin{abstract}
Our goal for this study was to determine whether the maturation of fat absorption in neonatal life is functionally related to an increased ability to hydrolyze dietary fat, to absorb long-chain fatty acids, or to do both. In 16 preterm and in eight term neonates, the intestinal ability to hydrolyze triacylglycerols and the capacity to absorb long-chain fatty acids were determined at several times between birth and 5 mo after the term age. These processes were compared with the percentage of fat absorption (formula-fed infants) or with fecal fat excretion (breast-fed infants). The functional capacity to digest triacylglycerols and to absorb the lipolytic products was evaluated by measuring serum concentrations of the lipolytic product $\left[1-{ }^{13} \mathrm{C}\right]$ palmitate after the enteral administration of tri-1- ${ }^{13} \mathrm{C}$ palmitoyl-glycerol. Longchain fatty acids absorption (i.e. independent of lipolysis) was determined by measuring serum concentrations of $\left[1-{ }^{13} \mathrm{C}\right]$ stearate after its enteral administration. The efficacy of fat absorption increased in preterm infants (formula-fed) from $91.2 \pm 1.1 \%$ (mean $\pm \mathrm{SEM})$ at $32.3 \mathrm{wk}$ postconceptional age (PCA) to 97.3
\end{abstract}

\section{ABSTRACT}

$\pm 0.6 \%$ at $53.6 \mathrm{wk}$ PCA $(p<0.001)$, and in term infants from $91.7 \pm 1.8 \%$ (40.0 wk PCA) to $97.4 \pm 1.3 \%$ (58.9 wk PCA, $p$ $=0.07)$. Both the serum concentration of $\left[1-{ }^{13} \mathrm{C}\right]$ stearate and that of $\left[1-{ }^{13} \mathrm{C}\right]$ palmitate appeared highly correlated with the efficacy of fat absorption ( $r=0.82, p=0.02$; and $r=0.91, p=0.004$; respectively) and with PCA ( $r=0.99, p<0.001$; and $r=0.85$, $p<0.02$; respectively). These results indicate that the functional development of fat absorption in preterm and term infants is related to the capacity to absorb long-chain fatty acids from the intestine. (Pediatr Res 51: 57-63, 2002)
LCFA, long-chain fatty acids
PCA, postconceptional age
${ }^{13}$ C-PA, $\left[1-{ }^{13} \mathrm{C}\right]$ palmitate
${ }^{13} \mathrm{C}-\mathrm{PG}$, tri- $\left[1-{ }^{13} \mathrm{C}\right]$ palmitoyl-glycerol
${ }^{13} \mathrm{C}-\mathrm{SA},\left[1-{ }^{13} \mathrm{C}\right]$ stearate

Efficient absorption of fat from the diet is important for energy supply, growth, and development, especially during development (1). At the neonatal age, and particularly in the case of prematurity, a considerable part of dietary fat is not absorbed from the intestine, but is excreted via the feces (2-5). Fat absorption involves digestion, requiring lipolysis by lipo-

Received May 3, 2000; accepted April 5, 2001.

Correspondence and reprint requests: H.J. Verkade, M.D., Institute for Liver, Intestine and Metabolic Disease, Department of Pediatrics, Laboratory Center CMC IV, Room Y.2115, Academic Hospital, P.O. Box 30.001, 9700 RB Groningen, The Netherlands; e-mail: h.j.verkade@med.rug.nl

Supported by Numico B.V. (Zoetermeer, the Netherlands). H.J.V. is a Clinical Research Fellow of the Dutch Organization for Scientific Research (NWO-KWO 904-62-135).

Presented in part at the 1999 Annual Meeting of the Society for Pediatric Research and published in abstract form (Pediatr Res 1999;45:290A).

Current address (W.P.F.F): Division of Neonatology, Department of Pediatrics, Academic Hospital Vrije Universiteit Amsterdam, P.O. Box 7057, 1007 MB Amsterdam, The Netherlands. lytic enzymes, and the subsequent intestinal absorption of the hydrolyzed fatty acids and monoacylglycerols (6). The uptake of lipolytic products encompasses intraluminal solubilization of lipolytic products, their subsequent translocation across the small intestine, and their incorporation into chylomicrons that are subsequently secreted into the lymph (7). The importance and relative contribution of incomplete digestion and a decreased ability for fatty acid absorption to the causes of increased fecal fat loss during (preterm) infancy is only partly understood. Several studies suggest that lipolysis of fats could be the rate-limiting step in (preterm) neonatal dietary fat absorption. In the human gastrointestinal system several lipases are active on dietary triacylglycerols: gastric lipase (8, 9 ), pancreatic (colipase-dependent) lipase $(10,11)$, and bile salt-stimulated lipase (12). Several investigators have demonstrated a decreased intraduodenal concentration of both pan- 
creatic lipase and bile salt-stimulated lipase in neonates (1318). Watkins et al. (19) found that a considerable part of neonatal fecal fat was composed of di- and triacylglycerols, also indicating that a diminished lipolytic activity contributes to the impaired fat absorption in neonatal life. Indirect support for insufficient lipolysis during early life could also be derived from the observation that fat absorption is more complete in breast-fed neonates, compared with formula-fed control infants, based on the presence of bile salt-stimulated lipase in human milk (20-23). Other studies, however, suggest uptake of lipolytic products could be rate-limiting. In one study on fecal fat composition of formula-fed neonates, more than $95 \%$ of the fatty acids were present in hydrolyzed, free form (3). Also, despite the presence of this additional lipase in human milk, human milk-fed neonates still have an increased fecal loss of dietary fat, especially with respect to LCFA. This phenomenon could be related to a decreased uptake capacity for LCFA in neonatal life, compared with later in development. In contrast to medium-chain fatty acids, LCFA are almost insoluble in water and heavily depend on solubilization, mainly by bile components, for their efficient transport through the aqueous phase of the small intestine (24). Several studies suggest that neonatal bile formation (in particular, intestinal bile salt concentration) is still insufficient for efficient and complete solubilization of LCFA $(2,25-28)$. At present, it is not known whether the translocation of LCFA across the small intestinal membrane or the intestinal capacity to assemble and secrete chylomicrons is rate-limiting in neonatal fat absorption.

It has not been demonstrated in a longitudinal fashion whether the maturation of fat absorption in neonatal life is functionally related to an increased capacity to hydrolyze dietary fat, to an increased ability to absorb LCFA, or to both. In the present study we aimed to address this issue. We chose to determine in a longitudinal fashion to what extent the efficacy of fat absorption in early life (analyzed by a fat balance method) correlated with the capability to hydrolyze triglycerides, composed of LCFA, and to take up LCFA. Our approach involved the longitudinal, simultaneous application of two tests, allowing estimation of the combined capability of the intestine to hydrolyze triacylglycerols and take up LCFA $\left({ }^{13} \mathrm{C}-\mathrm{PG}\right.$ test), and of the capability to take up LCFA per se $\left({ }^{13} \mathrm{C}\right.$-SA test). Insight into the causes of neonatal fat malabsorption may direct future strategies aimed at enhancing the efficacy of fat digestion and absorption.

\section{METHODS}

\section{Subjects and Formulas}

The Medical Ethics Committee of the Sophia Hospital Zwolle approved the study protocol. Informed consent was obtained from the parents of 16 preterm (28-37 wk of gestational age) and eight term (37-42 wk of gestational age) neonates. All children were healthy during the course of the study, did not have gastrointestinal disorders, and did not use antibiotics or other medications reported to influence the gastrointestinal tract. In preterm infants, fecal fat excretion (breast-fed infants) or fat absorption percentage (formula-fed infants) was analyzed at four consecutive test moments: at 1 wk postnatally in preterm infants (test moment A), at PCA term (test moment B), at PCA 46-49 wk (test moment C), and at PCA 53-59 wk (test moment D). Four neonates failed to complete the full study, three in the preterm group (only the first test moment completed) and one in the term group (failing the last test moment).

Dietary intake was recorded (volume, frequency, fat intake, composition of formula feeding). Dietary intake of fat from formula was based on intake of volume of enteral feeding and on the fat content of the specific formula used. The formulas used were Nenatal (Numico B.V., Zoetermeer, The Netherlands) at test moment $\mathrm{A}$, and, at later test moments, either Nutrilon Premium (Numico B.V.) in 14 infants or Frisolac (Friesland Coberco Dairy Foods, Meppel, The Netherlands) in three infants. The fat contents and compositions were as follows: Nenatal, $4.4 \mathrm{~g} / 100 \mathrm{~mL}$ (per $100 \mathrm{~g}$ fat: $1.3 \mathrm{~g}$ caprylic acid, $1.0 \mathrm{~g}$ capric acid, $11.6 \mathrm{~g}$ lauric acid, $4.2 \mathrm{~g}$ myristic acid, $21.4 \mathrm{~g}$ palmitic acid, $4.1 \mathrm{~g}$ stearic acid, $39.7 \mathrm{~g}$ oleic acid, $12.6 \mathrm{~g}$ linoleic acid, $1.25 \mathrm{~g} \alpha$-linolenic acid, other $3.3 \mathrm{~g}$ ); Nutrilon Premium, $3.5 \mathrm{~g} / 100 \mathrm{~mL}$ (per $100 \mathrm{~g}$ fat: $1.5 \mathrm{~g}$ caprylic acid, $1.3 \mathrm{~g}$ capric acid, $9.7 \mathrm{~g}$ lauric acid, $4.3 \mathrm{~g}$ myristic acid, $17.7 \mathrm{~g}$ palmitic acid, $3.5 \mathrm{~g}$ stearic acid, $45.5 \mathrm{~g}$ oleic acid, $11.4 \mathrm{~g}$ linoleic acid, $2.1 \mathrm{~g} \alpha$-linolenic acid, other $3.3 \mathrm{~g}$ ); and Frisolac, $3.5 \mathrm{~g} / 100 \mathrm{~mL}$ (per $100 \mathrm{~g}$ fat: $1.0 \mathrm{~g}$ caprylic acid, $1.0 \mathrm{~g}$ capric acid, $11.5 \mathrm{~g}$ lauric acid, $4.0 \mathrm{~g}$ myristic acid, $25.0 \mathrm{~g}$ palmitic acid, $3.3 \mathrm{~g}$ stearic acid, $38.0 \mathrm{~g}$ oleic acid, $13.5 \mathrm{~g}$ linoleic acid, $1.35 \mathrm{~g} \alpha$-linolenic acid, other $3.0 \mathrm{~g}$ ). Dietary intake of fat in breast-fed infants was not calculated given the difficulty of quantitating human milk fat intake during breast-feeding in a reliable fashion.

\section{${ }^{13}$ C-Labeled Substrates}

${ }^{13} \mathrm{C}-\mathrm{PG}$ and ${ }^{13} \mathrm{C}-\mathrm{SA}$ were purchased from Campro Scientific B.V. (Veenendaal, The Netherlands) and were both $99 \%$ ${ }^{13} \mathrm{C}$-enriched.

\section{Protocol}

At time $0 \mathrm{~h}$ of the test day, a combination of $10 \mathrm{mg} / \mathrm{kg}$ ${ }^{13} \mathrm{C}-\mathrm{PG}$ and $10 \mathrm{mg} / \mathrm{kg}{ }^{13} \mathrm{C}-\mathrm{SA}$, mechanically mixed in Nutricia Soy Emulsion (Numico B.V.) was administered per nasogastric tube. Within $1 \mathrm{~d}$ before administration a fecal sample was obtained, and $30 \mathrm{~min}$ before administration a blood sample was taken, to allow analysis of background enrichments of specific ${ }^{13} \mathrm{C}$-lipids. After administration, feces was collected for $72 \mathrm{~h}$ and frozen at $-20^{\circ} \mathrm{C}$ immediately after collection. At $4 \mathrm{~h}$ after administration, a blood sample was taken to analyze serum concentrations of the specific ${ }^{13} \mathrm{C}$-lipids. The time $4 \mathrm{~h}$ was chosen based on rat studies in which plasma concentrations of ${ }^{13} \mathrm{C}$-lipids were stable between 1 and $5 \mathrm{~h}$ after their intraduodenal administration (29).

\section{Measurements}

Serum lipids. Serum lipids were extracted, hydrolyzed, and methylated according to Lepage and Roy (30). Resulting fatty acid methyl esters were analyzed both by gas chromatography and by gas chromatography-combustion isotope ratio mass 
spectrometry, as detailed previously (31). Quantification of the resulting fatty acid methyl esters was performed with the use of heptadecanoic acid $\left(\mathrm{C}_{17: 0}\right)$ as an internal standard.

Fecal fat. Fecal fat was extracted from soiled diapers, according to the method of Beath et al. (32), and quantified (33). In formula-fed infants, the percentage of total fat absorption was calculated from the daily dietary fat intake and the daily fecal fat output and expressed as a percentage of amount ingested, according to the formula:

Percentage of total fat absorption

$$
\begin{gathered}
=\frac{\text { Fat intake }(\mathrm{g} / \mathrm{d})-\text { Fecal fat output }(\mathrm{g} / \mathrm{d})}{\text { Fat intake }(\mathrm{g} / \mathrm{d})} \times 100 \% \\
\text { Statistics }
\end{gathered}
$$

\section{Statistics}

The clinical data are reported as means \pm SEM. Correlations between variables were calculated with the least squares method and are expressed as Pearson's coefficient of variation $r$. Differences between means (one-way ANOVA) were exam- ined using SPSS 6.0 software (Chicago, IL, U.S.A.) and were considered statistically significant at the level of $p<0.05$.

\section{RESULTS}

Patient characteristics. Thirteen of the 16 enrolled preterm infants and seven of the eight enrolled term infants completed the longitudinal study. In the group of preterm infants, 11 infants were formula-fed at the first test moment, whereas all infants were formula-fed at the last test moment (Table 1). In the group of term neonates, seven were formula-fed at the time of enrollment. As expected, the average body weight at birth was significantly less in the preterm group $(1.31 \pm 0.08 \mathrm{~kg})$ compared with that in the term group $(3.27 \pm 0.35 \mathrm{~kg}$, formula-fed infants, $p<0.05$ ). During the course of the study, the mean growth rates were similar in preterm and term infants, associated with continuously lower body weights of preterm infants compared with those of term infants, even if corrected for the prematurity (Table 1).

Table 1. Patient characteristics

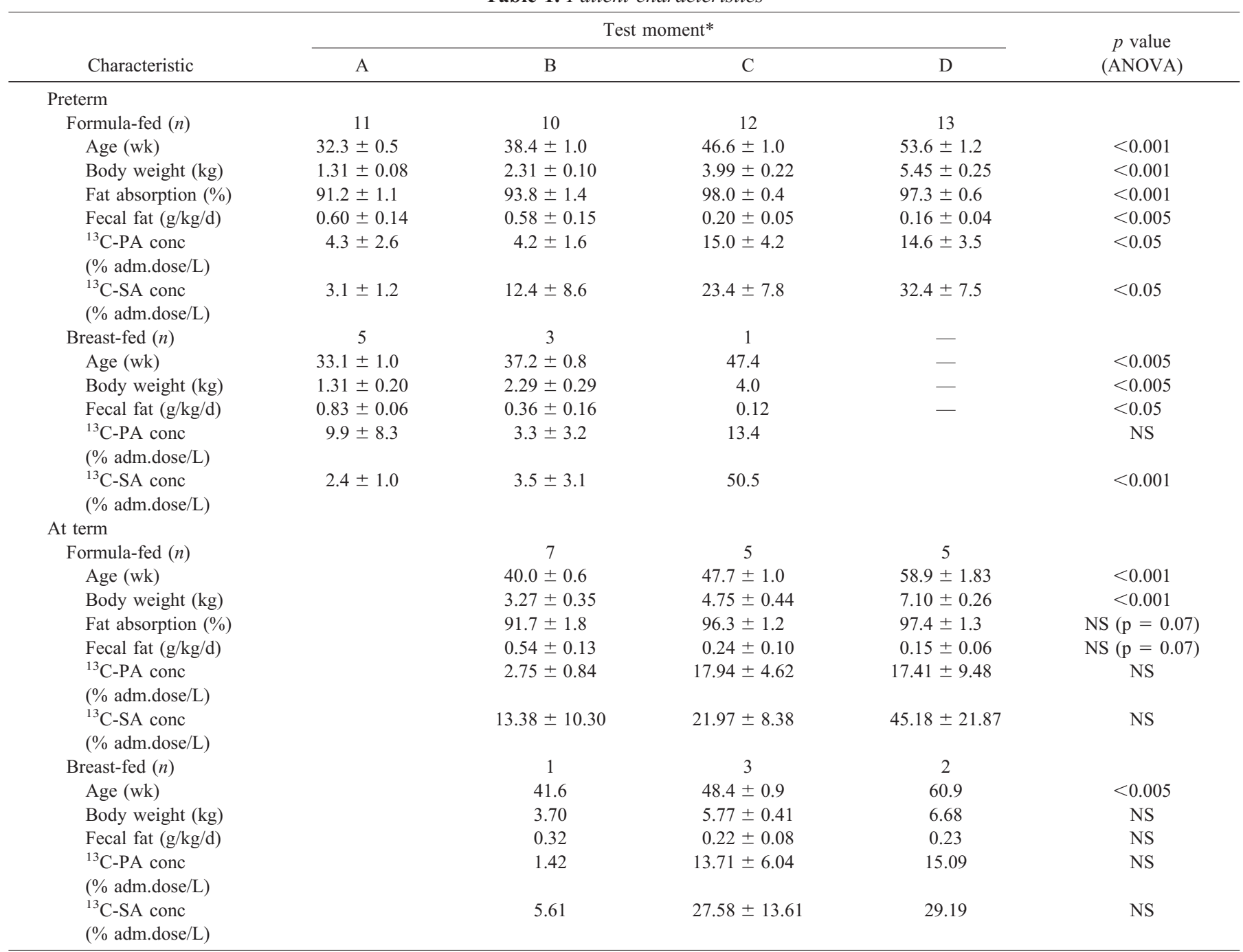

* In preterm infants, test moment A is first postnatal (preterm) week, B is corrected term age, C is corrected 6-8 wk, and D is corrected 13-19 wk. In term infants, test moment B is at term, C is 6-9 wk, and D is $13-19 \mathrm{wk}$.

Abbreviation used: $\%$ adm., $\%$ administered. 
Fat absorption percentage and fecal fat excretion during the first months of postnatal life. The percentage of fat absorption in preterm infants (formula-fed) increased from $91.2 \%$ at the first test moment to $97.3 \%$ at the last test moment $(p<0.001$; Table 1). In the group of term infants (formulafed), the percentage of total fat absorption also tended to increase during the study period, namely from $91.7 \%$ to $97.4 \%$, but the level of significance was not reached $(p=0.07)$. Results in preterm and term infants appeared very similar: at approximately $46 \mathrm{wk}$ PCA, the percentage of fat absorption reached adult levels, i.e. $>95 \%$ in each of the two groups, and remained constant thereafter. If one could (arbitrarily) fit the pooled data of term and preterm infants on a second-order polynomial curve, the equation would read [fat absorption percentage $]=63.16+1.17[\mathrm{PCA}]-0.01[\mathrm{PCA}]^{2}(r=0.89$, figure not shown).

The reliable quantitation of fat intake in breast-fed infants is extremely difficult. To be able to compare results in breast-fed infants with those in formula-fed infants, the daily fecal fat excretion was determined at each test moment, based on 3-d feces collection (Table 1). In both breast-fed and formula-fed infants, the fecal fat excretion decreased during development and, in formula-fed infants, appeared reciprocal to the observed fat absorption percentage. If one could (arbitrarily) fit the pooled data on fecal fat excretion and PCA on a second-order polynomial curve, the equation would read [fecal fat excretion] $=3.60-0.126[\mathrm{PCA}]+0.001[\mathrm{PCA}]^{2}(r=0.90$, figure not shown).

Combined capability for lipolysis of dietary triacylglycerols and subsequent LCFA uptake. The serum appearance of ${ }^{13} \mathrm{C}$-PA after enteral administration of ${ }^{13} \mathrm{C}$-PG provides information, which is related to both the functional capability of hydrolyzing triacylglycerols and the ability of the intestine to absorb. On pooling the data, dietary fat absorption percentage was correlated with serum concentrations of ${ }^{13} \mathrm{C}-\mathrm{PA}$ at $4 \mathrm{~h}$ after the administration of $10 \mathrm{mg} / \mathrm{kg}{ }^{13} \mathrm{C}-\mathrm{PG}(r=0.91, p=$ 0.004 ; Fig. $1 A$ ), with the following equation: $\left[{ }^{13} \mathrm{C}-\mathrm{PA}\right]=2.175$ $\times$ fat absorption percentage -195.95 . Linear regression calculated with individual data, i.e. four per preterm infant and three per term infant, results in $r=0.23, p=0.05$. Finally, the mean $r$ value for the individual linear regressions of the preterm infants (four data points per infant) is 0.39 .

To appreciate the notion that the data are distributed essentially in two clusters (Fig. 1A), the regression line is not drawn.

Intestinal absorption of LCFA. The serum concentration of ${ }^{13} \mathrm{C}$-SA in blood, after its enteral administration, provides information on the intestinal ability of LCFA uptake, as this fat does not require lipolysis before absorption. There appeared to be a high correlation between dietary fat absorption percentage and serum concentrations of ${ }^{13} \mathrm{C}-\mathrm{SA}$ at $4 \mathrm{~h}$ after the administration of $10 \mathrm{mg} / \mathrm{kg}{ }^{13} \mathrm{C}-\mathrm{SA}(r=0.82, p=0.02$; Fig. $1 B)$, with the following equation: $\left[{ }^{13} \mathrm{C}-\mathrm{SA}\right]=4.038 \times$ fat absorption percentage -362.32 . Linear regression calculated with individual data, i.e. four per preterm infant and three per term infant, results in $r=0.40, p<0.001$. Finally, the mean $r$ value for the individual linear regressions of the preterm infants (four data points per infant) is 0.58 .
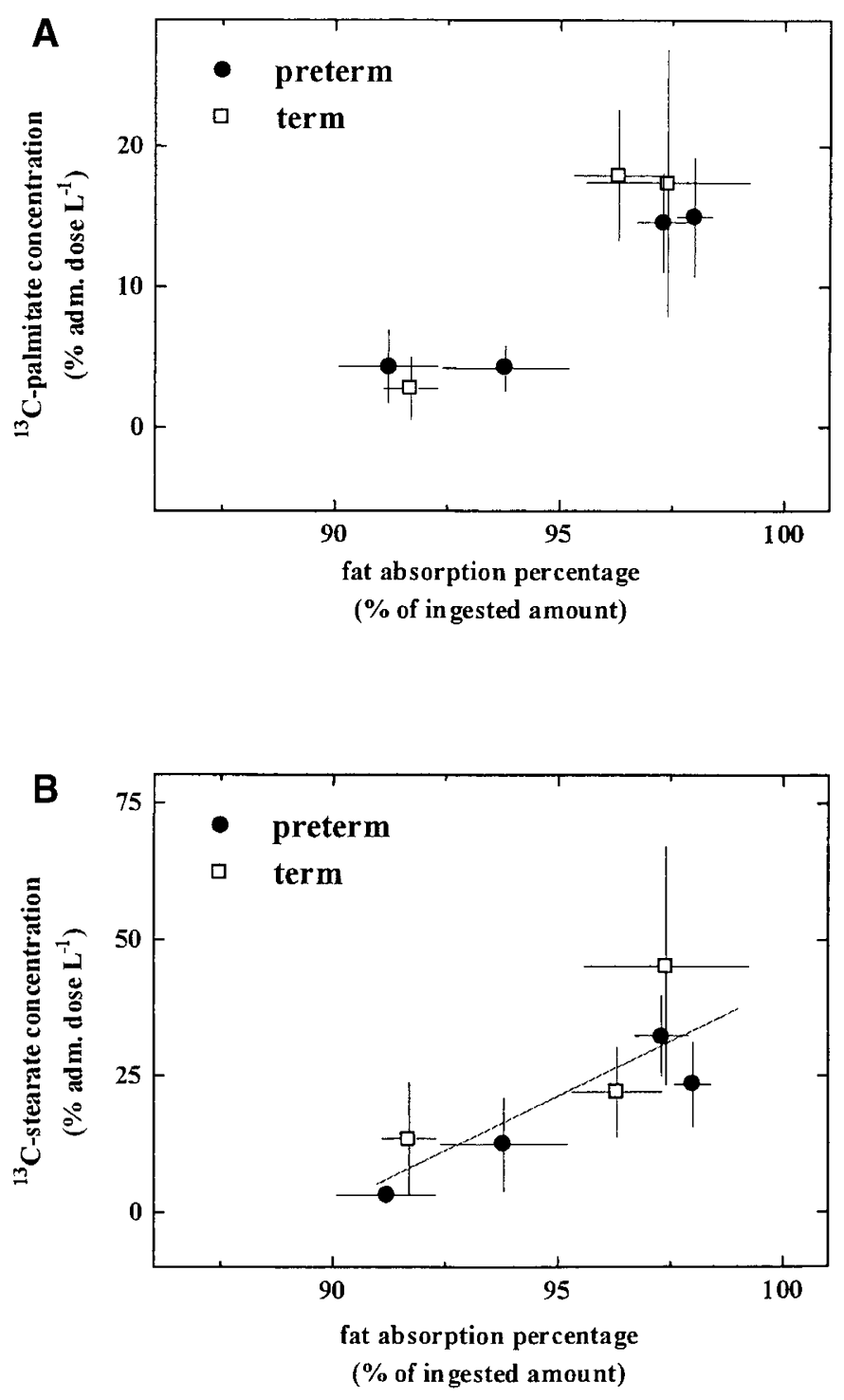

Figure 1. Relationship between fat absorption percentage and the $4 \mathrm{~h}$ serum concentration of ${ }^{13} \mathrm{C}$-PA $(A)$ or ${ }^{13} \mathrm{C}$-SA $(B)$ in formula-fed preterm $(-)$ or term $(\square)$ infants, after the administration of $\left[{ }^{13} \mathrm{C}\right]-\mathrm{PG}(10 \mathrm{mg} / \mathrm{kg})$ or ${ }^{13} \mathrm{C}-\mathrm{SA}(10$ $\mathrm{mg} / \mathrm{kg}$ ), respectively, at time 0 . Fat absorption percentage and serum ${ }^{13} \mathrm{C}-\mathrm{PA}$ or ${ }^{13} \mathrm{C}$-SA concentrations were determined on the basis of a 72-h fat balance as described in "Methods." The number of infants tested at each test moment varied from 10 to 13 and from five to seven, for preterm and term infants, respectively (Table 1). Linear regression analysis on pooled samples indicated significant correlations between fat absorption percentage and the 4-h serum concentration of either ${ }^{13} \mathrm{C}$-PA $(r=0.91, p=0.004 ; A)$ or ${ }^{13} \mathrm{C}$-SA $(r=0.82$, $p=0.02 ; B)$. Based on the apparent clustering of the data points in $A$, no regression line is depicted. Vertical and horizontal error bars represent SEM of ${ }^{13} \mathrm{C}$-PA or ${ }^{13} \mathrm{C}$-SA concentration and of fat absorption percentage, respectively.

Uptake of LCFA during development. In the study design chosen, term and preterm infants could be compared at similar PCA. The strikingly similar relationships obtained thus far in the two groups of infants indicated that the functional development of intestinal fat absorption is strongly related to PCA. To further investigate this relationship in more detail, we related the PCA with the serum concentration of ${ }^{13} \mathrm{C}-\mathrm{PA}$ (from ${ }^{13} \mathrm{C}$-PG; Fig. $2 A$ ) and ${ }^{13} \mathrm{C}$-SA (Fig. $2 B$ ) as a percentage of the 

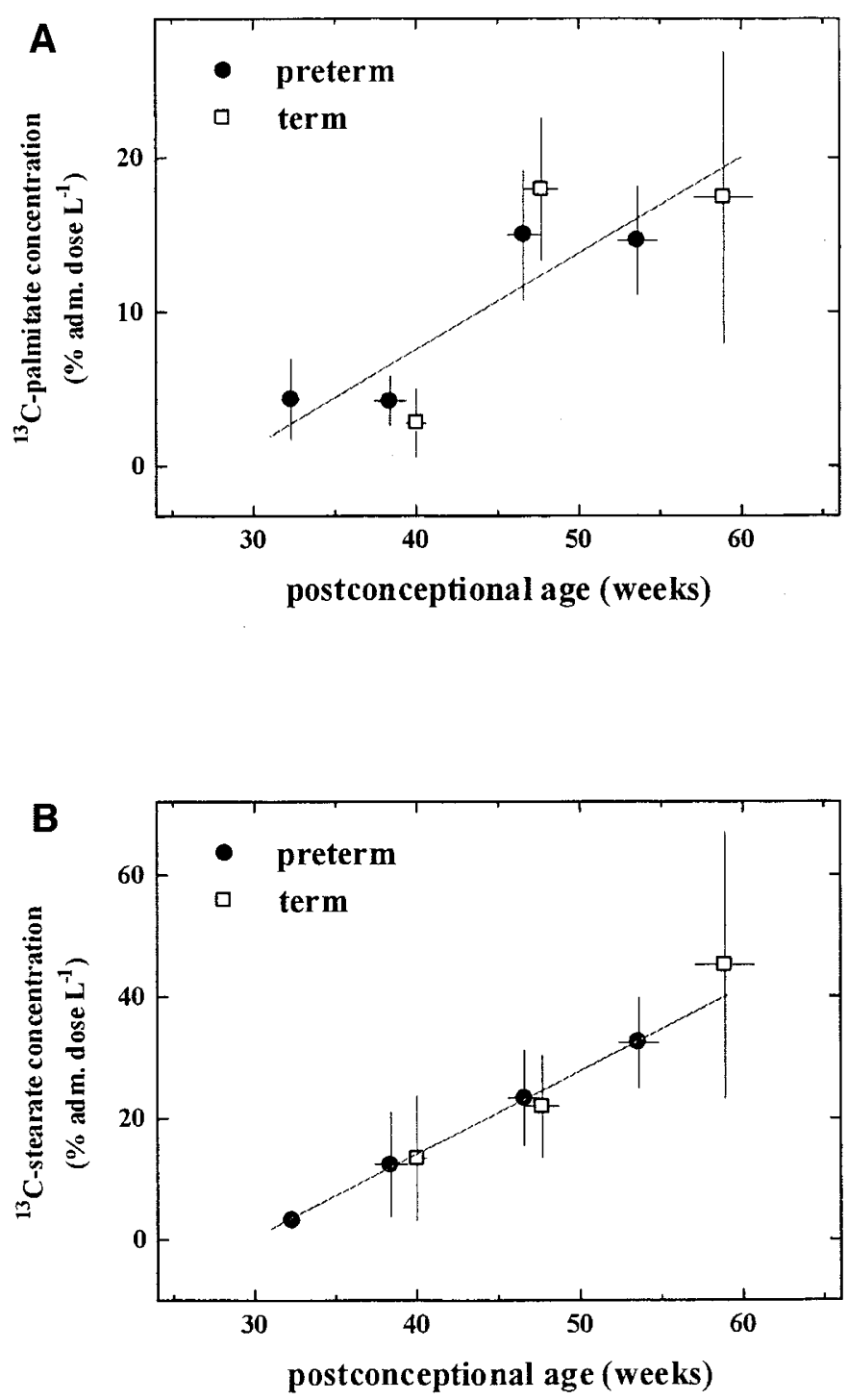

Figure 2. Relationship between PCA and the 4-h serum concentration of ${ }^{13} \mathrm{C}$-PA $(A)$ or ${ }^{13} \mathrm{C}$-SA $(B)$ in formula-fed preterm $(\bigcirc)$ or term $(\square)$ infants, after the administration of $\left[{ }^{13} \mathrm{C}\right]-\mathrm{PG}(10 \mathrm{mg} / \mathrm{kg})$ or ${ }^{13} \mathrm{C}-\mathrm{SA}(10 \mathrm{mg} / \mathrm{kg})$, respectively, at time 0 . Fat absorption percentage and serum ${ }^{13} \mathrm{C}$-PA or ${ }^{13} \mathrm{C}-\mathrm{SA}$ concentrations were determined on the basis of a 72-h fat balance as described in "Methods." The number of infants tested at each test moment varied from 10 to 13 and from five to seven, for preterm and term infants, respectively (Table 1). Linear regression analysis on pooled samples indicated significant correlations between PCA and the 4-h serum concentration of either ${ }^{13} \mathrm{C}-\mathrm{PA}(r$ $=0.85, p<0.02 ; A)$ or ${ }^{13} \mathrm{C}-\mathrm{SA}(r=0.99, p<0.001 ; B)$. Vertical and horizontal error bars represent SEM of ${ }^{13} \mathrm{C}$-PA or ${ }^{13} \mathrm{C}$-SA concentration and of PCA, respectively.

administered dose per liter in term and preterm (formula-fed) infants.

Linear regression analysis on pooled data resulted in a significant correlation between the PCA and serum concentrations of ${ }^{13} \mathrm{C}-\mathrm{PA}(r=0.85, p<0.02)$ or, even more strikingly, of ${ }^{13} \mathrm{C}$-SA $(r=0.99, p<0.001)$. Linear regression calculated with individual data, i.e. four per preterm infant and three per term infant, resulted in $r=0.41, p<0.001$, for ${ }^{13} \mathrm{C}-\mathrm{PA}$ and $r$ $=0.48, p<0.001$, for ${ }^{13} \mathrm{C}$-SA, respectively. Finally, the mean $r$ values for the individual linear regressions of the preterm infants (four data points per infant) were 0.41 for ${ }^{13} \mathrm{C}-\mathrm{PA}$, and
0.67 for ${ }^{13} \mathrm{C}$-SA. Particularly the results on ${ }^{13} \mathrm{C}$-SA support the concept that the observed increased capacity to absorb LCFA is mainly determined by postconceptional development, rather than, for example, postnatal development.

\section{DISCUSSION}

It has long been appreciated that the intestinal absorption of dietary fat occurs less efficiently in neonatal life than occurs from the age of approximately 4-6 mo. The contributions of low pancreatic enzyme secretion and bile production have been implied in the origin of less efficient fat absorption during early life. In the present study we aimed to determine the functional development of fat absorption in a longitudinal fashion in preterm and term infants, and to relate the efficacy of fat absorption to the functional capacities to hydrolyze dietary fat and to absorb (hydrolyzed) fatty acids from the intestinal lumen. At specific postnatal ages, two stable isotope tests were simultaneously performed in neonates in a longitudinal fashion. By directly measuring the appearance of stable isotopically labeled fatty acids in serum, rather than quantifying postabsorptive metabolites as ${ }^{13} \mathrm{CO}_{2}$ in breath, we expect to have overcome at least part of the difficulties that have been reported on quantitatively relating fat absorption with ${ }^{13} \mathrm{CO}_{2}$ expiration after enteral administration of labeled fat (34). The results from the two tests used in the present study, the ${ }^{13} \mathrm{C}-\mathrm{PG}$ test and the ${ }^{13} \mathrm{C}$-SA test (discussed below), provide strong indications that the development of fat absorption efficacy in preterm and term infants is not functionally related to the capability to hydrolyze dietary triacylglycerols, but rather to the intestinal capability to take up LCFA from the lumen.

The efficacy of fat absorption increased with either PCA (Table 1) or postnatal age (data not shown) in preterm and term infants, which was consistent with previously reported data (3, 4). It appeared that the infants seemed to reach mature levels of fat absorption already at the PCA of approximately $46 \mathrm{wk}$ (Table 1). The actual percentages of fat absorption at neonatal age were similar $(35,36)$ or slightly higher $(4,37,38)$ than those reported by others. It cannot be excluded that differences in formula composition or feeding regimen accounted for observed (slight) differences. The observed time-dependent development of fat absorption efficacy provided an excellent basis to determine the functional importance of increasing capacities to hydrolyze dietary fat and to take up fatty acids from the intestinal lumen. Initially, we aimed to compare the results obtained in formula-fed infants with those in breast-fed infants. However, the number of infants that were breast-fed for the entire length of the longitudinal study appeared too low to allow statistically reliable conclusions. It is nevertheless tempting to speculate that the present results obtained in formula-fed infants are likely to be similar in breast-fed infants. This speculation is supported by similar rates of fecal fat excretion in breast-fed and formula-fed infants during the course of the study, assuming that the daily fat intake in breast-fed infants is similar (Table 1). Ideally, the percentages of fat absorption should be compared in this respect, but the actual fat intake in breast-fed infants, which is needed to calculated the percentage of fat absorption, is difficult to obtain 
in a reliable fashion. Based on the precautions stated above, only data of the formula-fed infants were used for correlating efficacy of fat absorption with the serum appearance of either ${ }^{13} \mathrm{C}$-PA or ${ }^{13} \mathrm{C}$-SA.

By measuring serum concentrations of ${ }^{13} \mathrm{C}-\mathrm{PA}$ after the enteral administration of ${ }^{13} \mathrm{C}-\mathrm{PG}$, the functional capacities to hydrolyze triacylglycerols and to take up the lipolytic products were determined simultaneously. We reasoned that if either of the two functional processes (lipolysis and LCFA uptake) were rate-limiting for neonatal fat absorption, one would expect a strong correlation between efficacy of fat absorption and the serum ${ }^{13} \mathrm{C}-\mathrm{PA}$ concentration, as measured during the functional development of neonatal fat absorption during 4-6 mo. The explanation for this concept is that the serum appearance of ${ }^{13} \mathrm{C}$-PA from ${ }^{13} \mathrm{C}$-PG does not only depend on efficient lipolysis in the intestinal lumen, but also on the intestinal ability to absorb LCFA. The ${ }^{13} \mathrm{C}-\mathrm{SA}$ test would then discriminate whether the lipolytic capacity or, alternatively, the LCFA uptake capability could be identified as the most important contributor to functional development of fat absorption. Because ${ }^{13} \mathrm{C}-\mathrm{SA}$ is already in the form of an absorbable, free fatty acid, its appearance in serum is not expected to be related to intestinal lipolytic activity (39). Except for lipolysis, however, all other processes involved in fatty acid absorption are very similar for ${ }^{13} \mathrm{C}$-SA and for (triglyceride-derived) ${ }^{13} \mathrm{C}-\mathrm{PA}$, both being saturated LCFA. If the development of lipolytic ability would govern the actual fat absorption percentage at different test moments, one would expect that the fat absorption percentage would be strongly correlated with serum ${ }^{13} \mathrm{C}-\mathrm{PA}$ concentrations, but not with serum ${ }^{13} \mathrm{C}$-SA concentrations. Alternatively, if the fat absorption percentage in early life were regulated by the intestinal capability to take up LCFA, one would expect that the fat absorption percentage was correlated with serum concentrations of ${ }^{13} \mathrm{C}-\mathrm{PA}$, and also with those of ${ }^{13} \mathrm{C}-\mathrm{SA}$. The latter situation appeared to apply, i.e. fat absorption percentage correlated with both serum ${ }^{13} \mathrm{C}-\mathrm{PA}$ concentration and ${ }^{13} \mathrm{C}-\mathrm{SA}$ concentration (Fig. 1). Present results allow us to speculate that the reported increase in intestinal lipolytic ability during the first months after birth in preterm and term neonates (13-15) is not governing neonatal fat absorption efficacy.

The choice for palmitate and stearate as marker molecules was based on several reasons. First, palmitate and stearate are rather similar in physicochemical characteristics (both being saturated LCFA). Second, the saturated nature of the molecules prevented the risk of oxidation of the molecules during storage or handling. Third, both fatty acids are normally present in infant formulas in appreciable amounts. Finally, although the percentage of stearate absorption is usually lower than that of palmitate, the absorption percentages of these fatty acids paralleled each other in groups of neonates fed different infant formulas (40).

In the formulas used, the contents of palmitic acid were higher than those of stearic acid. Also, the serum concentrations of palmitic acid are 2- to 3-fold higher than those of stearic acid. The administration of similar molar amounts of the ${ }^{13} \mathrm{C}$-fatty acids was therefore expected to result in lower serum enrichments for palmitic acid than for stearic acid.
Except for the first test moment in preterm infants, lower serum enrichments of palmitic acid than of stearic acid were indeed observed (Table 1). Yet, the absolute differences in stearic acid and palmitic acid enrichments did not interfere with the interpretation of the results. Rather than comparing the absolute enrichments of palmitic acid with those of stearic acid, the time-dependent change of the enrichment of each fatty acid during the postnatal period was the aim of study.

The time point of the serum sampling, namely $4 \mathrm{~h}$ after administration, was arbitrarily chosen, partly based on ${ }^{13} \mathrm{C}-\mathrm{PA}$ experiments in an animal model (29) and on a $\left[{ }^{13} \mathrm{C}\right]$ linoleic acid absorption study in children with cystic fibrosis (31). We do realize that the observations in the rat cannot be directly extrapolated to the human situation and that results obtained for $\left[{ }^{13} \mathrm{C}\right]$ linoleic acid absorption may not be similar for ${ }^{13} \mathrm{C}-\mathrm{PA}$ or ${ }^{13} \mathrm{C}$-SA. It is in fact likely that in the present study, the infants differed in, for example, gastric emptying, both among each other as well as at the various test moments. To correct for these variances, we could have compared the ratios between the serum concentrations of the two ${ }^{13} \mathrm{C}$-lipids, as both lipids are expected to be affected to similar extents. Yet, strong correlations were already obtained without executing this correction. A theoretical alternative for the use of plasma values would have been the quantitation of the unabsorbed ${ }^{13} \mathrm{C}$-fatty acids in the feces. However, the correlation between unabsorbed (fecal) concentrations of ${ }^{13} \mathrm{C}$-fatty acids and dietary fat absorption has been demonstrated to be weak, probably attributable to tracer effects and to compensatory ${ }^{13} \mathrm{C}$-fatty acid absorption in the distal parts of the small intestine $(29,39$, 41-44).

The intestinal ability to take up LCFA can be subdivided into luminal solubilization (mainly by bile components), subsequent translocation across the apical membrane of the intestinal mucosal cell, and, finally, mucosal reacylation, incorporation into chylomicrons, and secretion into the lymph. From the present study we cannot conclude which of these processes is responsible for the observed correlation between efficacy of fat absorption and intestinal capability to take up LCFA. However, the bile and bile salt compositions have been reported to change during development, both in preterm and term neonates $(2,25,27,28)$, which could be related to the presently obtained results. To elucidate the possible rate-limiting role of biliary LCFA solubilization in a similarly functional study, longitudinal investigations of bile composition in relation to the capability of LCFA uptake would be informative.

Acknowledgments. The authors thank Carin Bunkers and Enna Smink for recruiting and including patients during the course of this study, Mariska Westers and Henk Elzinga for excellent technical assistance, Peter Voshol for statistical analysis, Richard van Lingen for advice and fruitful discussions, and John Lynch for a critical review of the manuscript.

\section{REFERENCES}

1. Carey MC, Small DM, Bliss CM 1983 Lipid digestion and absorption. Annu Rev Physiol 45:651-677

2. Signer E, Murphy GM, Edkins S, Anderson CM 1974 Role of bile salts in fat malabsorption of premature infants. Arch Dis Child 49:174-180 
3. Verkade HJ, Hoving EB, Muskiet FA, Martini IA, Jansen G, Okken A, Vonk RJ, Bijleveld CM 1991 Fat absorption in neonates: comparison of long-chain-fatty-acid and triglyceride compositions of formula, feces, and blood. Am J Clin Nutr 53:643651

4. Verkade HJ, van Asselt WA, Vonk RJ, Bijleveld CM, Fernandes J, de Jong H, Fidler V, Okken A 1989 Fat absorption in premature infants: the effect of lard and antibiotics. Eur J Pediatr 149:126-129

5. Hamosh M 1996 Digestion in the newborn. Clin Perinatol 23:191-209

6. Carey MC, Hernell O 1992 Digestion and absorption of fat. Semin Gastroint Dis $3: 189-208$

7. Verkade HJ, Minich DM, Bijleveld CMA, van Aalderen WM, Stellaard F, Vonk RJ, Laseur M, Kalivianakis M 2000 Impaired uptake of long-chain fatty acids contributes to fat malabsorption in paediatric patients with cystic fibrosis. In: Northfield TC Ahmed HA, Jazrawi RP, Zentler-Munro PL (eds) Bile Acids in Hepatobiliary Disease. Kluwer Academic Publishers, Dordrecht, pp 286-300

8. Fredrikzon B, Hernell O 1977 Role of feeding on lipase activity in gastric contents. Acta Paediatr Scand 66:479-484

9. Armand M, Hamosh M, Mehta NR, Angelus PA, Philpott JR, Henderson TR, Dwyer NK, Lairon D, Hamosh P 1996 Effect of human milk or formula on gastric function and fat digestion in the premature infant. Pediatr Res 40:429-437

10. Kolacek S, Puntis JW, Lloyd DR, Brown GA, Booth IW 1990 Ontogeny of pancreatic exocrine function. Arch Dis Child 65:178-181

11. Zoppi G, Andreotti G, Njai DM, Gaburro D 1972 Exocrine pancreas function in premature and full term neonates. Pediatr Res 6:880-886

12. Hernell O, Blackberg L 1994 Molecular aspects of fat digestion in the newborn. Acta Paediatr Suppl 405:65-69

13. Boehm G, Bierbach U, Delsanto A, Moro G, Minoli I 1995 Activities of trypsin and lipase in duodenal aspirates of healthy preterm infants: effects of gestational and postnatal age. Biol Neonate 67:248-253

14. Boehm G, Borte M, Mueller H, Moro G 1995 Activities of trypsin and lipase in duodenal aspirates of preterm infants: influence of dietary protein and fat composition. Am J Clin Nutr 61:524-527

15. Boehm G, Bierbach U, Senger H, Jakobsson I, Minoli I, Moro G, Raiha NC 1991 Activities of lipase and trypsin in duodenal juice of infants small for gestational age. J Pediatr Gastroenterol Nutr 12:324-327

16. Lebenthal E, Choi TS, Lee PC 1981 The development of pancreatic function in premature infants after milk-based and soy-based formulas. Pediatr Res 15:12401244

17. Lebenthal E, Leung YK 1986 Neonatal exocrine pancreatic secretory immaturity: potential mechanisms and investigative approaches. J Pediatr Gastroenterol Nutr $5: 1-4$

18. Lebenthal E, Lee PC 1980 Development of functional responses in human exocrine pancreas. Pediatrics 66:556-560

19. Watkins JB, Bliss CM, Donaldson Jr RM, Lester R 1974 Characterization of newborn fecal lipid. Pediatrics 53:511-515

20. Hernell O, Blackberg L, Bernback S 1989 Digestion of human milk fat in early infancy. Acta Paediatr Scand Suppl 351:57-62

21. Van den Boom MA, Groot Wassink M, Roelofsen B, Tijburg LB, Op den Kamp JA 1995 In vivo turnover of 1,2-dipalmitoylphosphatidylcholine and sphingomyelin in rabbit erythrocytes. Biochim Biophys Acta 1258:265-271

22. Hernell O, Blackberg L 1982 Digestion of human milk lipids: physiologic significance of sn-2 monoacylglycerol hydrolysis by bile salt-stimulated lipase. Pediatr Res $16: 882-885$

23. Alemi B, Hamosh M, Scanlon JW, Salzman-Mann C, Hamosh P 1981 Fat digestion in very low-birth-weight infants: effect of addition of human milk to low-birth-weight formula. Pediatrics 68:484-489

24. Westergaard H, Dietschy JM 1976 The mechanism whereby bile acid micelles increase the rate of fatty acid and cholesterol uptake into the intestinal mucosal cell. $\mathrm{J}$ Clin Invest 58:97-108
25. Hammons JL, Jordan WE, Stewart RL, Taulbee JD, Berg RW 1988 Age and diet effects on fecal bile acids in infants. J Pediatr Gastroenterol Nutr 7:30-38

26. Watkins JB, Szczepanik P, Gould JB, Klein P, Lester R 1975 Bile salt metabolism in the human premature infant. Preliminary observations of pool size and synthesis rate following prenatal administration of dexamethasone and phenobarbital. Gastroenterology 69:706-713

27. Watkins JB, Ingall D, Szczepanik P, Klein PD, Lester R 1973 Bile-salt metabolism in the newborn. Measurement of pool size and synthesis by stable isotope technic. N Engl J Med 288:431-434

28. Heikura S, Simila S, Finni K, Maentausta O, Janne O 1980 Cholic acid and chenodeoxycholic acid concentrations in serum during infancy and childhood. Acta Paediatr Scand 69:659-662

29. Kalivianakis M, Minich DM, Havinga R, Kuipers F, Stellaard F, Vonk RJ, Verkade HJ 2000 Detection of impaired intestinal absorption of long-chain fatty acids: validation studies of a novel test in a rat model of fat malabsorption. Am J Clin Nutr $72: 174-180$

30. Lepage G, Roy CC 1986 Direct transesterification of all classes of lipids in a one-step reaction. J Lipid Res 27:114-120

31. Kalivianakis M, Minich DM, Bijleveld CMA, van Aalderen WM, Stellaard F, Laseur M, Vonk RJ, Verkade HJ 1999 Fat malabsorption in cystic fibrosis patients receiving enzyme replacement therapy is due to impaired intestinal uptake of long-chain fatty acids. Am J Clin Nutr 69:127-134

32. Beath SV, Willis KD, Hooley IM, Brown GA, Kelly DA, Booth IW 1993 New method for determining faecal fat excretion in infancy. Arch Dis Child 69:138-140

33. Van den Kamer JH, ten Bokkel Huinink H 1949 Rapid method for the determination of fat in feces. J Biol Chem 177:347-355

34. Manson WG, Coward WA, Harding M, Weaver LT 1999 Development of fat digestion in infancy. Arch Dis Child Fetal Neonatal Ed 80:F183-F187

35. Carnielli VP, Luijendijk IH, van Goudoever JB, Sulkers EJ, Boerlage AA, Degenhart HJ, Sauer PJ 1996 Structural position and amount of palmitic acid in infant formulas: effects on fat, fatty acid, and mineral balance. J Pediatr Gastroenterol Nutr 23:553560

36. Chappell JE, Clandinin MT, Kearney-Volpe C, Reichman B, Swyer PW 1986 Fatty acid balance studies in premature infants fed human milk or formula: effect of calcium supplementation. J Pediatr 108:439-447

37. Atkinson SA, Bryan MH, Anderson GH 1981 Human milk feeding in premature infants: protein, fat, and carbohydrate balances in the first two weeks of life. J Pediatr 99:617-624

38. Finley AJ, Davidson M 1980 Bile acid excretion and patterns of fatty acid absorption in formula-fed premature infants. Pediatrics 65:132-138

39. Kalivianakis M, Elstrodt J, Havinga R, Kuipers F, Stellaard F, Sauer PJ, Vonk RJ, Verkade HJ 1999 Validation in an animal model of the carbon 13-labeled mixed triglyceride breath test for the detection of intestinal fat malabsorption. J Pediatr 135:444-450

40. Tomarelli RM, Meyer BJ, Weaber JR, Bernhart FW 1968 Effect of positional distribution on the absorption of the fatty acids of human milk and infant formulas. J Nutr 95:583-590

41. Murphy JL, Jones AE, Stolinski M, Wootton SA 1997 Gastrointestinal handling of $\left[1-{ }^{13} \mathrm{C}\right]$ palmitic acid in healthy controls and patients with cystic fibrosis. Arch Dis Child 76:425-427

42. Murphy JL, Laiho KM, Jones AE, Wootton SA 1998 Metabolic handling of ${ }^{13} \mathrm{C}$ labelled tripalmitin in healthy controls and patients with cystic fibrosis. Arch Dis Child 79:44-47

43. Murphy JL, Jones A, Brookes S, Wootton SA 1995 The gastrointestinal handling and metabolism of $\left[1-{ }^{13} \mathrm{C}\right]$ palmitic acid in healthy women. Lipids 30:291-298

44. Minich DM, Kalivianakis M, Havinga R, Van Goor H, Stellaard F, Vonk RJ, Kuipers F, Verkade HJ 1999 Bile diversion in rats leads to a decreased plasma concentration of linoleic acid which is not due to decreased net intestinal absorption of dietary linoleic acid. Biochim Biophys Acta 1438:111-119 